\title{
Time-sequence Photography to Record Germination Events
}

\author{
T.N. Tomas ${ }^{1}$ \\ Department of Fruit and Vegetable Sciences, Cornell University Ithaca, \\ NY 14853
}

\author{
A.G. Taylor ${ }^{2}$ \\ Department of Horticultural Sciences, New York State Agricultural \\ Experiment Station, Geneva, NY 14456
}

\section{L.A. Ellerbrock ${ }^{3}$}

Department of Fruit and Vegetable Sciences, Cornell University, Ithaca, NY 14853

\section{Additional index words. lettuce, Lactuca sativa, radicle emergence}

Time to germination is an important aspect of seed vigor (Association of Official Seed Analysts, 1983). The objective of this study was to develop a method of collecting data that would: 1) record the condition of all the seeds in a germination experiment simultaneously; 2) facilitate rapid automated determinations; and 3) allow the seeds to remain undisturbed throughout the duration of the experiment. Here we report the design and operation of a system employing timesequence photography to record germination events at specific time intervals using $35 \mathrm{~mm}$ photography technology.

A no. CS-3 copy stand (Testrite Inst. Co., Newark, N.J.) was mounted on a $152 \times 61$ $\times 2$-cm CDX sheet of plywood. A Minolta MAXXUM 7000 (Minolta Corp., Ramsey, N.J.) $35 \mathrm{~mm}$ camera with an AF 50-mm f2.8 Macro lens was equipped with a Minolta Program Back 70 and attached to the adjustable mount of the copy stand. The camera was positioned with the lens $81 \mathrm{~cm}$ above germination boxes $(11.5 \times 11.5 \mathrm{~cm})$ arranged in a $3 \times 4$ pattern, each containing 50 seeds on blue blotters (Anchor Paper, St. Paul, Minn.).

A germination chamber, $50 \times 38 \times 80$ cm (length $\times$ width $\times$ height), was constructed from $0.3-\mathrm{cm}$-thick plexiglass. A 1.0 $\times 0.6-\mathrm{cm}$ ridge of plexiglass was attached to a $0.6 \times 50 \times 38-\mathrm{cm}$ sheet of plate glass with silicone glue to form the base (Fig. 1). The ridge was designed to hold the top chamber in place and provide a shallow, water-tight reservoir. The bottom of the chamber was covered with a single layer of saturated blotter paper to help maintain high humidity within the chamber. The entire ap-

Received for publication 6 May 1991. Accepted for publication 12 Nov. 1991. The cost of publishing this paper was defrayed in part by the payment of page charges. Under postal regulations, this paper therefore must be hereby marked $a d$ vertisement solely to indicate this fact.

${ }^{1}$ Former Graduate Student.

${ }^{2}$ Associate Professor of Seed Science, to whom reprint requests should be addressed.

${ }^{3}$ Associate Professor of Vegetable Crops. paratus was housed in a Percival (Boone, Iowa) walk-in growth chamber set at a constant 20C in darkness.

Two rods, $122 \mathrm{~cm}$ in length, were attached to the plywood base in a vertical position. A Vivitar 283 electronic flash unit (Vivitar Corp., Santa Monica, Calif.) was attached near the top of each rod. One flash unit was connected to the camera with a cable, and the second flash unit was fitted with a Vivitar SL-2 remote flash trigger.

The Program Back 70 was programmed in the intervalometer mode to expose one frame every $2 \mathrm{~h}$, starting $\approx 2 \mathrm{~h}$ before the first seeds were expected to germinate and continuing for $48 \mathrm{~h}$. The camera was operated in the manual focus mode with an $\mathrm{f}$ stop value of 5.6 at 1/60 sec using Kodachrome ASA 64 slide film (Eastman Kodak Co., Rochester, N.Y.).

Two thermometers were placed in the chamber with the sensing bulbs at opposite sides of the chamber to detect temperature gradients. Each box was weighed at the beginning and end of each experiment to detect differential loss of moisture, which might be associated with location of the boxes within the chamber. A nondigital watch was placed

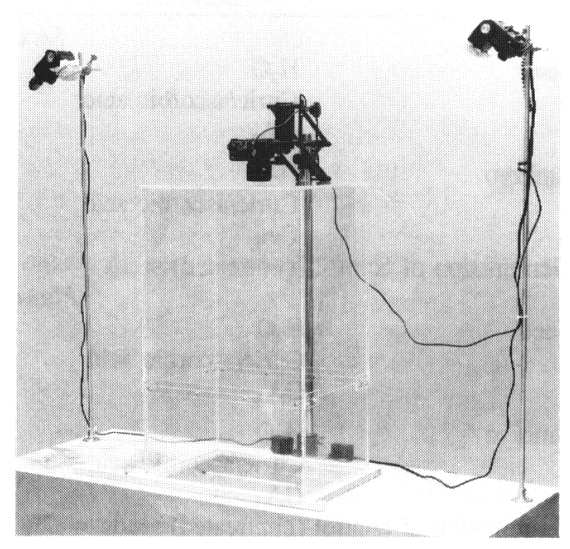

Fig. 1. The germination chamber with photographic equipment used to record germination events. in the chamber to record the time that each slide was taken. With this information, it was possible to determine any changes in temperature within the chamber over time or drying effects within the individual boxes due to location within the chamber.

A study was conducted to evaluate uniformity of test results obtained within the chamber and between replications over time. Fifty 'Montello' lettuce (Lactuca sativa L.) seeds (Harris-Moran Seed Co., Rochester, N.Y.) were placed in uniformly spaced rows on the blotters in boxes. Boxes were placed in the base of the chamber, and the entire experiment was replicated over time on four occasions. Slides were projected in sequence to estimate the time required for each seed to germinate. Time, in hours, for $50 \%$ of the radicles to emerge $\left(\mathrm{T}_{50}\right)$ and time spread, in hours, for $10 \%$ to $90 \%$ of the radicles to emerge $\left(\mathrm{T}_{10}-{ }_{90}\right)$ from the seeds were calculated (Hill et al., 1989). The total percent germination was determined after $48 \mathrm{~h}$. There were no significant differences $(P=0.05)$ in $\mathrm{T}_{50}, \mathrm{~T}_{10-90}$, or total germination due to location within the chamber or between replications over time. The overall uniformity of the data indicates that this technique is a useful tool in gathering germination data and that it was repeatable over time. This system could be used to record germination events in a range of species that germinate readily on blotters. Preliminary studies have revealed that this technique can be used for cucumber (Cucumis sativus L.) and tomato (Lycopersicon esculentum Mill) seeds without modification. Use of a shorter chamber allowed focal distance to be decreased, and the germination rate of tobacco (Nicotiana tobacum L.) seeds was successfully documented. This system could also be used to record germination events from experiments to study other seed and environmental variables such as seed quality, cultivar, temperature, and medium water potential.

Data acquisition from $35-\mathrm{mm}$ frames is possible with computer image analysis (IA) systems, which would eliminate the timeconsuming and tedious job of manually transcribing the data from slides. Further developments in the use of IA (McCormac et al., 1990) may facilitate the direct recording of germination events without the use of slides. At present, the system employing time-sequence photography described here can be used to document germination events over time at a relatively low cost with existing 35-mm photography technology.

\section{Literature Cited}

Association of Official Seed Analysts. 1983. Seed vigor testing handbook. Assn. Offic. Seed Analysts.

Hill, H.J., A.G. Taylor, and T.-G. Min. 1989. Density separation of imbibed and primed vegetable seeds. J. Amer. Soc. Hort. Sci. 114:661665.

McCormac, A.C., P.D. Keefe, and S.R. Draper. 1990. Automated vigor testing of field vegetables using image analysis. Seed Sci. Technol. 18:103-112. 